\title{
Salt marsh sediment bacterial communities maintain original population structure after transplantation across a latitudinal gradient
}

\author{
Angus Angermeyer Corresp., 1, 2, 3 , Sarah C Crosby ${ }^{1,2,4}$, Julie A Huber ${ }^{2,5}$ \\ 1 Ecology and Evolutionary Biology, Brown University, Providence, RI, United States \\ 2 Josephine Bay Paul Center, Marine Biological Laboratory, Woods Hole, MA, United States \\ 3 Plant and Microbial Biology, University of California, Berkeley, Berkeley, CA, United States \\ 4 Harbor Watch, Earthplace Inc., Westport, CT, United States \\ 5 Marine Chemistry and Geochemistry, Woods Hole Oceanographic Institution, Woods Hole, MA, United States \\ Corresponding Author: Angus Angermeyer \\ Email address: angus.angermeyer@gmail.com
}

Dispersal and environmental selection are two of the most important factors that govern the distributions of microbial communities in nature. While dispersal rates are often inferred by measuring the degree to which community similarity diminishes with increasing geographic distance, determining the extent to which environmental selection impacts the distribution of microbes is more complex. To address this knowledge gap, we performed a large reciprocal transplant experiment to simulate the dispersal of US East Coast salt marsh Spartina alterniflora rhizome-associated microbial sediment communities across a latitudinal gradient and determined if any shifts in microbial community composition occurred as a result of the transplantation. Using bacterial 16S rRNA gene sequencing, we did not observe large-scale changes in community composition over a fivemonth S. alterniflora summer growing season and found that transplanted communities more closely resembled their origin sites than their destination sites. Furthermore, transplanted communities grouped predominantly by region, with two sites from the north and three sites to the south hosting distinct bacterial taxa, suggesting that sediment communities transplanted from north to south tended to retain their northern microbial distributions, whereas south to north maintained a southern distribution. A small number of potential indicator 16S rRNA gene sequences had distributions that were strongly correlated to both temperature and nitrogen, indicating that some organisms are more sensitive to environmental factors than others. These results provide new insight into the microbial biogeography of salt marsh sediments and suggest that established bacterial communities in frequently-inundated environments may be both highly resistant to invasion and resilient to some environmental shifts. However, the extent to which environmental selection impacts these communities is taxon specific and variable, 
highlighting the complex interplay between dispersal and environmental selection for microbial communities in nature. 
1 Salt marsh sediment bacterial communities maintain original population structure after transplantation across a latitudinal gradient

3

4 Angus Angermeyer ${ }^{1,2,3}$, Sarah C. Crosby ${ }^{1,2,4}$, Julie A. Huber ${ }^{2,5}$

5

$6 \quad{ }^{1}$ Ecology and Evolutionary Biology, Brown University, Providence, RI, United States

$7 \quad{ }^{2}$ Josephine Bay Paul Center, Marine Biological Laboratory, Woods Hole, MA, United States

$8{ }^{3}$ Current address: Plant and Microbial Biology, University of California Berkeley, Berkeley, CA,

9 United States

$10{ }^{4}$ Current address: Harbor Watch, Earthplace Inc., Westport CT, United States

$11{ }^{5}$ Marine Chemistry and Geochemistry, Woods Hole Oceanographic Institution, Woods Hole,

12 MA, United States

13

14 Corresponding Author:

15 Angus Angermeyer

16 Email address: angus.angermeyer@gmail.com 


\section{Abstract}

18 Dispersal and environmental selection are two of the most important factors that govern the 19 distributions of microbial communities in nature. While dispersal rates are often inferred by 20 measuring the degree to which community similarity diminishes with increasing geographic distance, determining the extent to which environmental selection impacts the distribution of microbes is more complex. To address this knowledge gap, we performed a large reciprocal transplant experiment to simulate the dispersal of US East Coast salt marsh Spartina alterniflora rhizome-associated microbial sediment communities across a latitudinal gradient and determined if any shifts in microbial community composition occurred as a result of the transplantation. Using bacterial 16S rRNA gene sequencing, we did not observe large-scale changes in community composition over a five-month $S$. alterniflora summer growing season and found that transplanted communities more closely resembled their origin sites than their destination sites. Furthermore, transplanted communities grouped predominantly by region, with two sites from the north and three sites to the south hosting distinct bacterial taxa, suggesting that sediment communities transplanted from north to south tended to retain their northern microbial distributions, whereas south to north maintained a southern distribution. A small number of potential indicator 16S rRNA gene sequences had distributions that were strongly correlated to both temperature and nitrogen, indicating that some organisms are more sensitive to environmental factors than others. These results provide new insight into the microbial biogeography of salt marsh sediments and suggest that established bacterial communities in frequently-inundated environments may be both highly resistant to invasion and resilient to some environmental shifts. However, the extent to which environmental selection impacts these communities is taxon specific and variable, highlighting the complex interplay between dispersal and environmental selection for microbial communities in nature. 
42

43

44

45

46

47

48

49

50

51

52

53

54

55

56

57

58

59

60

61

62

63

64

65

66

67

68

69

70

71

72

73

74

75

76

77

78

79

80

81

82

83

84

85

86

87

\section{Introduction}

It is increasingly clear that microbial taxa vary in their ability to disperse across landscapes, and that environmental conditions as well as biological mechanisms can influence community dynamics post-dispersal. Investigating the interplay between these variables is key to building better models of microbial biogeography. A wide variety of studies, spanning coastal salt marshes, oceans, and forest rainwater deposits often indicate a taxa-area relationship for bacteria, with both geographic distance and environmental factors giving rise to uneven spatial distributions of microbes in nature (Angermeyer et al. 2015; Horner-Devine et al. 2004; Zinger et al. 2014; Bell et al. 2005). These distance-decay relationships are thought to be driven by the interplay between the mechanisms of dispersal, environmental selection, genetic drift, and random mutation (Hanson et al., 2012; Nemergut et al., 2013). However, the details of how each mechanism or combination of mechanisms affects the composition of complex natural communities is not well understood. For instance, both selection and drift act upon microorganisms after a dispersal event, but the rates of those events are likely to be highly variable across the diversity of taxa that comprise a complex microbial community (van der Gast, 2014). This variability can be caused by neutral effects such as abundance (higher abundance taxa have a better chance of dispersing) (Livermore and Jones, 2015) or due to active dispersal-mechanism phenotypes (such as biofilm attachment/detachment) (McDougald et al., 2011). Taxa that are in low abundance can be more strongly influenced by bottleneck effects in comparison to more abundant, highly active groups. A further challenge in studying the mechanisms that drive distance-decay patterns is in the detection of subtle genetic flows caused by drift and mutation in a diverse natural community (Andam et al., 2016).

Here, we build upon our previous work on microbial biogeography in a salt marsh model system (Angermeyer et al. 2015) to examine dispersal and adaptation of the resident bacterial communities in more detail using a reciprocal transplant approach. Reciprocal transplantation is a well-established tool in traditional "macro" ecology, but is infrequently utilized in microbial biogeography. Reciprocal transplantation effectively simulates a large dispersal event and affords the opportunity to then observe the effects of such an event on microbial communities (Balser and Firestone, 2005; Waldrop and Firestone, 2006). Transplants leverage both common garden and environmental treatment techniques to test for the selection effects of one environment on multiple communities as well as the effects of multiple environmental gradients on the replicates of each community (Reed and Martiny, 2007). However, transplant experiments generally cannot directly observe the rates of genetic drift and mutation due to the timescales over which these phenomena likely manifest, as well as the high frequency and depth of DNA sequencing that would be required to detect them.

Previous studies explored how the functional parameters of microbial communities can shift (Gasol et al., 2002; Comte et al., 2013) and how community taxonomic composition can change (Oakley et al., 2010; Bell, 2010) after transplantation. Microbial reciprocal transplants have been performed across a wide range of environmental systems including: alpine soils (Rui et al., 2015), wetland sediments (Reed and Martiny, 2013; Morrissey and Franklin, 2015), and decomposing plant litter (St John et al., 2011), among others. These studies employed diverse methodological approaches to reciprocal transplantation which includes sealing samples to prevent invasion from host site communities (with nutrient permeability) (Bell, 2010; Reed and Martiny, 2013; Morrissey and Franklin, 2015), inverting sea-ice cores to alter the photosynthetic 
88

89

90

91

92

93

94

95

96

97

98

99

100

101

102

103

104

105

106

107

108

109

110

111

112

113

114

115

116

117

118

119

120

121

122

123

124

125

126

127

128

129

130

131

132

133

regime vertically (Martin et al., 2011), and swapping gut microbiota between gnotobiotic zebra fish and mice (Rawls et al., 2006). The duration of the transplant (time between transplantation and sample recovery) experiments also varies widely, with studies ranging from 2 weeks (Reed and Martiny, 2013) to 17 years (Bond-Lamberty et al., 2016). While a relatively low number of microbial reciprocal transplant studies have been performed, each study lends important insight into the ecology and biogeography of microbial communities of a specific environment.

In this study, we considered transplants as simulated dispersal events and asked the question: Do microbial communities undergo compositional changes in response to mass dispersal events between similar environments (salt marshes) across a latitudinal gradient? If so, do these responses correlate to temperature, other environmental shifts, and/or the geographic transplantdistance experienced by the dispersed community? We considered four hypotheses for changes that could occur between transplanted communities in a new host site versus control communities that remained in their original marsh site: 1) No change - The transplanted community will appear identical to communities from its original site. This is the null hypothesis indicating no invasion and no environmental selection occurred in the transplanted community;

2) Total adoption - The transplanted community will change to appear identical to the communities in its new host marsh. This result indicates that either the transplanted sediments were completely invaded and replaced by the surrounding marsh communities, or that environmental selection is overwhelmingly able to reshape the community structure, or a combination of both; 3) Random shift - The transplanted community will change to something distinct from both origin and host communities. In this case, the cause could be either a fundamental problem with the transplantation methodology (e.g. contamination) or the effects of unknown and unmeasured environmental variables; And 4) Host shift - The transplanted community will change to something in between origin and host communities. This result indicates that invasion and/or environmental selection is affecting the transplanted community, but it is either recalcitrant to total adoption or the process takes longer than the duration of the experiment.

Here we present results of this reciprocal transplant experiment of Spartina alterniflora rhizomeassociated bacterial communities between five salt marshes along the US East Coast to examine the roles that dispersal and environmental selection play in driving microbial community structure. The approach builds on previous work of biogeography of microbial communities in salt marsh sediments and provides new insights into the impacts of microbial dispersal and selection in the environment.

\section{Materials and Methods}

Reciprocal transplantation

Fifteen sediment cores with associated live Spartina alterniflora roots and stems were collected from each of five U.S. east coast salt marshes in March 2010 (15/marsh; 75 total): Waquoit Bay National Estuarine Research Reserve (WB) - East Falmouth, MA [41.5806N, 70.5198W]; Prudence Island National Estuarine Research Reserve (PI) - Portsmouth, RI [41.6249N, 71.3228W]; St. Jones River National Estuarine Research Reserve (JR) - Dover, DE [39.0889N, 75.4363W]; Rachel Carson National Estuarine Research Reserve (RC) - Beaufort, NC [34.7221N, 76.6798W]; ACE Basin National Estuarine Research Reserve (AB) - Bennett's Point, SC [32.5576N, 80.4365W] (Figure 1). All cores were collected from within monospecific 
134 stands of tall-form clonal S. alterniflora with similar peak stem heights that were collected at

135 least 1 meter away from the nearest creek-bank and in a region of each marsh that experienced

136 semi-diurnal tides with less than 20\% submergence per day (Crosby et al., 2015; Crosby et al.,

137 2017).

138

139

140

Sediment cores measured $8 \mathrm{~cm}$ in diameter by $\sim 25 \mathrm{~cm}$ long and were extracted from the marsh using serrated stainless-steel manual corer, taking care not to disturb the internal structure.

141

142 Triplicate cores from each marsh site were transplanted in a fully factorial manner to every other marsh site, including a control set re-planted into the origin site. For example: from the Waquoit Bay salt marsh site, three cores were transplanted to Prudence Island, three to St. Jones River, three to Rachel Carson, three to ACE Basin, and three were replanted back into Waquoit Bay. The same process was repeated for 15 cores from each other site. All transplanted and replanted cores were maintained at approximately $20^{\circ} \mathrm{C}$ (air-conditioned during day, cool ambient at night) and covered with damp cloth during transport to retain moisture. Cores were kept in these conditions for 1-7 days before replanting, depending on the travel distance between sites. Cores were planted by creating a fresh core-hole in the host marsh at the appropriate depth, and carefully placing one transplanted or replanted core in each hole. Due to local site restrictions, a thin layer of high-permeability, 'weed-blocking' ground cloth was placed around all cores transplanted into the St. Jones River marsh.

All 75 cores were recovered from each marsh in October 2010, a 6-month transplant duration. Approximately 2 grams of sediment were collected with a sterilized scoopula from an undisturbed region $20 \mathrm{~cm}$ below the surface and in the center of each core. Each sample was suspended in LifeGuard (Mo Bio, Carlsbad, CA) to preserve its nucleic acids. Sediment was collected in an identical fashion from triplicate, newly extricated 'pristine' cores at each site. The total number of sediment samples was therefore 18 per marsh ( 3 from each of the other 4 sites [12 total], 3 from that sites replanted controls, and 3 pristine new samples from the site). Two transplant samples were unable to be recovered (PI-to-JR \#2 and WB-to-AB \#3), resulting in a total of 88 samples.

\section{Environmental measurements}

Three sediment samples per site ( $\sim 5$ grams each) were collected in October 2010 when the transplants were recovered and immediately frozen on dry ice. These samples were pooled by site, dried at $70^{\circ} \mathrm{C}$ for 4 days, and were analyzed according to Meyer et al., 2013 using a Thermo Scientific CN Analyzer (Model Flash 2000) to determine concentrations of total carbon and nitrogen. Mean air temperature over the course of the transplant experiment was collected from the nearest National Oceanic and Atmospheric Administration weather station ([Site: Station ID] WB: WAXM3, PI: PTCR1, JR: DRSD1, RC: BFTN7, AB: ACXS1). Mean average salinity was determined from measurements taken in March, May, July, and October at each site over the same time period using a YSI Model 85 water quality meter (YSI, Yellow Springs, OH) (Crosby et al., 2017). Pairwise Mantel tests (Mantel, 1967) and linear regressions were performed between all measured environmental variables to identify possible correlations. extraction kits (MoBio, Carlsbad, CA), eluted in the provided buffer, and quantified on a 
180 Nanodrop 2000 (Thermo Scientific, Wilmington, DE). Extracted DNA samples were diluted to 181 achieve $\sim 10-15 \mathrm{ng} / \mu 1$ standardized concentrations for downstream applications. DNA was stored 182 at $-80^{\circ} \mathrm{C}$.

183

16S rRNA gene PCR, sequencing and analysis

186

187 Bacterial amplicon generation and sequencing was performed as described previously (Angermeyer et al., 2015). Briefly, the v4v5 regions of the bacterial 16S rRNA gene were amplified and prepared according to Huse and colleagues (2014). Sequencing was performed on an Illumina MiSeq sequencer (Illumina, San Diego, CA) at the W. M. Keck Ecological and Evolutionary Genetics Facility at the Marine Biological Laboratory in Woods Hole, MA. Reads were merged and quality checked using illumina-utils (Eren, Vineis, et al., 2013) (code available at https://github.com/meren/illumina-utils) using a modification of earlier methods (Huse et al., 2007). Sequence data was subsampled (rarefication) to ensure even sampling across all samples. Operational Taxonomic Unit (OTU) clustering at 97\% similarity and taxonomic assignments were performed using QIIME (pick_otus.py, method: uclust) (Caporaso, Kuczynski, et al., 2010) and GAST (Huse et al., 2008). Sequences are publicly available at the 'The Visualization and Analysis of Microbial Population Structures' (VAMPS) website (https://vamps.mbl.edu/) (Huse et al., 2014) under project title: "JAH_TRP_Bv4v5" and are deposited at the NCBI SRA under accession number PRJNA384656.

199

\section{Environmental correlations of controls}

201

202

203

204

16S rRNA gene OTU data for replanted controls and pristine controls were extracted from the complete data set across all sites and used to construct Bray-Curtis dissimilarity matrices in mothur (Schloss et al., 2009). This was completed for all OTUs as well as for the top ten most abundant OTUs across all samples, which produced four distinct matrices (Replant_all, Replant_top, Pristine_all, and Pristine_top). Pairwise linear regressions were generated in $\mathrm{R}$ (Team, 2008) using the 'pairs()' function between each control matrix and geographic distance (to minimize skew, all dissimilarity matrices and GeoDist were natural log transformed for this analysis (Martiny et al., 2011). A pairwise Mantel test was performed concurrently with 999 permutations.

\section{Ordination analyses}

The 16S rRNA gene OTU data were parsed into two subsets: all OTUs (the entire dataset), and top 10 OTUs (the ten most abundant OTUs across all sites and samples). For each ordination plot, the specific samples of interest were extracted from a subset (e.g. only pristine and transplant control samples). Non-metric multidimensional scaling (nMDS) calculations were performed using the 'nmds()' function in mothur with 999 iterations.

\section{Potential Indicator OTUs}

The observed abundances of each specific OTU across all samples were compared to the degree of environmental change and geographic distance measured between a transplant sample's origin site and destination site. For each sample, this provided an $(\mathrm{x}, \mathrm{y})$ coordinate data-point which, when taken together, created a multi-coordinate dataset. To have spatial consistency between datasets, it was necessary to calculate percent OTU abundance per sample (observed OTU abundance in a sample/total abundance of that OTU across all samples). Similarly, environmental data was natural $\log$ transformed to facilitate comparison between variables. For 
226

227

228

229

230

231

232

233

234

235

236

237

238

239

240

241

242

243

244

245

246

247

248

249

250

251

252

253

254

255

256

257

258

259

260

261

262

263

264

265

266

267

268

269

270

271

example, if an OTU abundance was 100 in transplant sample 'WB-to-AB' and that OTU total abundance was 1000 across all samples, the percent OTU abundance per sample would be $10 \%$. If temperature was the variable being considered, the ln-transformed temperature increase from site $\mathrm{WB}$ to $\mathrm{AB}$ is: $\ln \left[24.2^{\circ} \mathrm{C}\right]-\ln \left[17.1^{\circ} \mathrm{C}\right]=0.296$ (Table 1$)$. The $(\mathrm{x}, \mathrm{y})$ coordinate would therefore be $(0.296,0.10)$ with abundance as the dependent variable. If the next sample to be evaluated were AB-to-WB (the opposite direction) and the OTU abundance in transplant sample 'AB-toWB' was $10(10 / 1000=0.01)$, then the coordinate would be $(-0.296,0.01)$. For each OTU and for each environmental variable (excluding percent carbon), an $\mathrm{x}-\mathrm{y}$ dataset was populated in this fashion. The results were also curated to only include OTUs that occurred in $>95 \%$ of the samples (at least 84 of 88 samples).

A least-squares linear regression test was then performed on each dataset using the 'scipy.stats.linregress()' function in the SciPy Python module (Jones et al., 2001) to calculate the slope and R-squared value of the best linear fit. To minimize the possibility of type I error (false positives) when searching for correlations in a large dataset (63337 OTUs x 4 variables $=253348$ regressions), a Bonferroni correction was applied to an initially conservative significance cutoff $(\alpha=0.001)$ resulting in a per-hypothesis corrected-confidence level of $\alpha=3.9 \mathrm{e}^{-9}(\alpha / \#$ regression tests). Therefore, a regression's correlation was rejected if a two-sided hypothesis test (null: slope $=0$ ) returned a $\mathrm{p}$-value $\geq 3.9 \mathrm{e}^{-9}$, which approximately corresponds to R-squared values $>$ 0.40 .

\section{Results}

Transplant recovery

Upon completion of the transplant experiment, the cores were still distinct from the surrounding host marsh sediments, with a visibly clear delineation between core and core hole and little to no root intrusion between core and surrounding sediment. Most were recovered with only minor recoring. However, there was some variability in the structure of the recovered cores. The cores originating from Waquoit Bay, Prudence Island, and Jones River (the northern three sites) were almost entirely intact regardless of the destination host site. Cores from Rachel Carson and especially Ace Basin suffered some loss of sediment due presumably to tidal erosion. Northern sediments have more peat and greater root structure whereas southern sites are muddier and tend to have fewer, larger roots (Crosby et al., 2015). Nevertheless, in all cases there was ample core remaining to recover the necessary amount of sediment from $20 \mathrm{~cm}$ below the surface from the uncontaminated center of the core. It was also observed that the survival of the Spartina plants themselves varied by origin. The further south a plant was transplanted, the more likely the stems were to die, however plants originating from the southern sites showed little to no mortality regardless of how far north they were transplanted (Crosby et al., 2017).

\section{Environmental characteristics}

Variability between sites was similar to observations made at the same sites during other parts of the season (Angermeyer et al., 2015). Air temperature ranged from $17.1-24.2^{\circ} \mathrm{C}$, as expected along the latitudinal gradient. Salinity was lowest at JR (10.7 ppt) due to its greater distance from the ocean. The other sites were closer to the coast and had higher salinity (25.1-32.3 ppt). Percent total nitrogen by weight $(0.51-1.34 \%)$ and carbon by weight $(8.59-23.58 \%)$ were lowest in the southern three sites and relatively higher in the north with a sharp increase at PI (Table 1). Pairwise mantel tests $(\mathrm{M})$ and linear regression $\left(\mathrm{R}^{2}\right)$ confirmed that temperature and geographic 
272 distance were very strongly correlated $\left(\mathrm{M}=0.98, \mathrm{R}^{2}=0.96, \mathrm{P} \leq 0.05\right)$ as well as nitrogen and carbon

$273\left(\mathrm{M}=0.97, \mathrm{R}^{2}=0.94, \mathrm{P} \leq 0.05\right.$, Supp. Figure 1). There were also significant correlations between

274 both carbon/nitrogen and geodist/temperature pairs $\left(M=0.35-0.49, R^{2}=0.12-0.24, P \leq 0.05\right.$, Supp.

275 Figure 1).

276

277

Bacterial community composition

278 The average concentration of extracted DNA was $49.12 \mathrm{ng} / \mu 1$ (stdev \pm 24.47 ) before

279 standardization. Sequencing of the v4v5 region of the bacterial 16S rRNA gene generated

$2803,434,579$ high quality sequences with an average length of 376 base pairs. There were an

281 average of 39,029 (stdev $\pm 11,212$ ) sequences in each sample before rarefying to an even depth of

28214,376 sequences per sample. After rarefaction, taxonomic identification revealed 57,667 total

283 Operational Taxonomic Units (OTUs) across samples at 97\% similarity. Of these, 17,154

284 singletons were removed, leaving 40,513 OTUs for subsequent analyses.

285

286

287

288

289

290

291

292

293

294

295

296

297

298

299

300

301

302

303

304

305

306

307

308

309

310

311

312

313

314

315

316

317

Analyses of the 16S rRNA gene data revealed a clear difference in bacterial community composition between the sediment samples that originated in the northern sites (WB, PI) versus the three southern sites (JR, RC, AB) (Figure 2). When a sample originated in the south, its bacterial community tended to be dominated by Gammaproteobacteria (average relative abundance across all samples from each site: JR-50\%, RC-43\%, AB-33\%). Within this class, one OTU belonging to the genus Vibrio (OTU\# 32074) dominated in these southern samples (average relative abundance across all samples from each site: JR-20\%, RC-23\%, AB-23\%). In contrast, Gammaproteobacteria were at much lower relative abundances (7-8\%) in the two northern sites, and the relative abundance of the same Vibrio OTU was also extremely low $(<0.3 \%)$. However, the northern sites were more abundant in Anaerolineae (phylum Chloroflexi) (average relative abundance across all samples from each site: WB-16\%, PI-12\%) and Deltaproteobacteria (average relative abundance across all samples from each site: WB-17\%, PI-17\%) compared to the southern sites, which averaged 3-6\% for Anaerolineae and 8-10\% for Deltaproteobacteria. These trends in relative abundance were consistent for all transplant samples and pristine samples.

\section{Analysis of control samples}

Mantel tests and linear regressions of $16 \mathrm{~S}$ rRNA gene OTUs determined that the transplant control (cores re-planted in the same marsh) and pristine control (new cores collected from each marsh at the end of the transplant experiment) microbial communities were correlated when comparing all OTUs (Replant_all vs. Pristine_all: $\mathrm{M}=0.69, \mathrm{R}^{2}=0.47, \mathrm{P} \leq 0.05$ ). These statistical tests further showed that datasets comprised of only the top ten most abundant 16S rRNA gene OTUs across all samples were also correlated between replant and pristine controls (Replant_top vs. Pristine_top: $\mathrm{M}=0.71, \mathrm{R}^{2}=0.50, \mathrm{P} \leq 0.05$ ) (Supp. Figure 2). Additionally, the pristine datasets exhibited a significant correlation with the geographic distance between sites, which is consistent with previous findings (Angermeyer et al., 2015) (Pristine_all vs. GeoDist: $\mathrm{M}=0.82, \mathrm{R}^{2}=0.68$, $\mathrm{P} \leq 0.05$ ) and (Pristine_top vs. GeoDist: $\left.\mathrm{M}=0.75, \mathrm{R}^{2}=0.56, \mathrm{P} \leq 0.05\right)$ (Supp. Figure 2).

\section{Ordination analysis}

Non-metric multidimensional scaling (nMDS) plots of the Bray-Curtis similarities for 16S rRNA gene OTUs between transplant control and pristine control samples illustrated that the two controls grouped together by site (Figure 3A, B). This was true for both all OTUs and the top ten 
318 most abundant OTUs, although the stress value was relatively high for all OTUs (Figure 3 A, B).

319 When expanded to include all transplant samples (as well as both controls), labeled by origin site

320 (Figure $3 \mathrm{C}, \mathrm{D})$, the transplant communities grouped more closely with the sites they originated

321 from, particularly when only the top ten most abundant OTUs were considered. However, when

322 labeled by destination site, there were no obvious grouping patterns (Supp. Figure 3).

323

324

325

326

327

328

329

330

331

332

333

334

335

336

337

338

339

340

341

342

343

344

345

346

347

348

349

350

351

352

353

354

355

356

357

358

359

360

361

362

\section{Potential Indicator OTUs}

The linear regression analysis identified four potential correlations among 3 16S rRNA gene OTUs (Chloroflexi; Anaerolineae; Anaerolineales; Anaerolinaceae [OTU\# 21858], Proteobacteria; Gammaproteobacteria; Vibrionales; Vibrionaceae; Vibrio [OTU\# 32074], and Proteobacteria; Deltaproteobacteria; Desulfobacterales; Desulfobacteraceae [OTU\# 13670]) and a change with a specific environmental variable (Supp. Table 1, Figure 4). Two correlations were with change in temperature (Anaerolinaceae, Vibrio) and two in percent nitrogen (Anaerolinaceae, Desulfobacteraceae). Due to the environmental correlation between carbon and nitrogen, carbon results were excluded from the results. The R-squared values of the regressions ranged from 0.41 to 0.59 and the slopes -3.53 to 4.01 . The taxonomic identity of the OTUs was determined to the family level for Anaerolinaceae and Desulfobacteraceae, and to genus for the Vibrio OTU. The total percent abundances across all samples for each OTU were $0.075 \%$ for Anaerolinaceae, $0.241 \%$ for Desulfobacteraceae-, and $10.3 \%$ for Vibrio.

\section{Discussion}

Although distance-decay analyses are an excellent approach to observing the $\beta$-diversity relationships of microbial communities separated by a range of geographic distances, they can only examine a 'snapshot' of microbial distributions in time (Martiny et al., 2011). Performing multiple experiments over time can provide additional insight into how communities change with temporal or seasonal patterns (Fortunato et al., 2013), but such experiments do not consider the role that dispersal plays in microbial community distribution patterns. To address this need, we performed a reciprocal transplant experiment to simulate the dispersal of salt marsh sediment microbial communities across a latitudinal gradient and over the course of a summer growing season in an attempt to disentangle the roles that dispersal, environmental selection, and geographic distance play in driving microbial community changes. Transplant experiments can be difficult to interpret in many cases due to the challenges of controlling for multiple, diverse environmental variables (Reed and Martiny, 2007). However, the broad, ecosystem-scale environmental similarities (as compared to most other microbial transplant study systems) over a large latitudinal gradient made these marshes well-suited to a reciprocal transplantation experiment. We tested the acceptability of our core-transplant method by comparing communities from control sediments (removed from each marsh and replanted back into the same site) versus communities from undisturbed 'pristine' control samples collected at the end of the experiment. An ordination analysis demonstrated that the replanted controls did not diverge greatly from the natural marsh community state and therefore the methods were likely sound (Figure $3 \mathrm{~A}, \mathrm{~B}$ ). The controls used in this study also allowed us to examine the distance-decay relationships between the same sites as in our previous study (although with a smaller data set) during a different season (Angermeyer et al., 2015), and we confirmed that the trend observed is seasonally consistent (Supp. Figure 2). 
363 This study was designed to determine if microbial community composition changed after

364 transplantation into a new host marsh and to what, if any, degree several measured

365 environmental differences between origin and destination marshes influenced microbial

366 community structure. After five months in a host marsh, transplanted communities most closely

367 resembled the current state of the sites from which they originated (Figure 2). Of the four

368 hypotheses presented in the introduction (no change, total adoption, random shift, and host shift),

369 the null hypothesis of no change best matches our results. However, ordination analysis revealed

370 that transplanted communities grouped by latitudinal region, with Waquoit Bay and Prudence

371 Island in the north, and Jones River, Rachael Carson, and Ace Basin in the south (Figure 3 C, D).

372 In effect, this meant that sediment communities transplanted from north to south tended to retain

373 their northern microbial distributions, whereas south to north maintained a southern distribution.

374 This trend was especially clear when we focused on the top ten most abundant OTUs (Figure

375 3D). It is also important to note that the two northern sites are the closest together spatially and

376 distance decay curves suggest they have a lower barrier to dispersal between them than between

377

378

379 Several recent studies have shown that transplanted communities retain compositions more

380 closely associated with the communities at their origin sites than the host locations. In one

381 experiment, deep-sea methane seep carbonates were reciprocally transplanted between high and

382 low activity methane seeps (Case et al., 2015). The authors found evidence that microbial

383 carbonate communities were highly resistant to invasion and maintained $49-90 \%$ of their original

384 'high-activity site' taxa after 13 months in a low-activity site. They speculated that these taxa

385 may be "adapted to cycles of seep quiescence and activation," which may provide ecological

386 advantages in fluctuating environments. A second study exchanged soil samples between

387 calcareous and siliceous glacier forefields for 15 months and found that while seasonal

388 precipitation caused some temporary diversification of the transplanted communities, in the end,

389 no large effect of the transplantation was observed on either soil type (Lazzaro et al., 2011). In a

390 third study, dryland soils were transplanted across an elevation gradient, and the authors found

391 that although respiration rates of soils tended to match the host site controls, the microbial

392 community composition retained a composition most similar to their origin site controls. This

393 result was especially surprising given that the duration of the transplantation experiment was 17

394 years. It is generally hypothesized that this experiment's duration would be ample to fully

395 acclimatize a transplanted sample to both microbial invasion and seasonal patterns (Bond-

396 Lamberty et al., 2016). However, this result highlights that actual rates of drift, mutation,

397 dispersal and selection are poorly constrained for microbes in the natural world, including how

398 they vary between microbial lineages and habitats.

399

400

401

402

403

404

405

406

407

408

In our study, the distribution of bacterial OTUs between north and south sites revealed that the southern sites were highly enriched for one OTU belonging to the genus Vibrio, while the northern sites had a higher relative abundance of an Anaerolinaceae OTU and a Desulfobacteraceae OTU. We speculated that the pattern of Vibrio abundance, in particular, was driven by temperature differences between southern and northern sites as correlations between the abundances of various Vibrio taxa and temperature in late summer are well described in the mid-Atlantic U.S. east coast (Pfeffer et al., 2003; Thompson et al., 2004). To confirm if this temperature effect was responsible for the distributions of Vibrio in our data and to determine if other OTUs exhibited correlations with any of the environmental variables, we performed a 
409 linear regression analysis with strict threshold cutoffs to only consider the most highly correlated 410 OTU-environment relationships for further analysis (Supp. Table 1). Our analysis confirmed that 411 one Vibrio OTU had a statistically significant correlation with the change in temperature 412 experienced by each transplant (Figure 4D). The negative slope indicated that as the difference in 413 temperature from origin site to destination site increased, the Vibrio OTU was less abundant, 414 meaning that in sample cores transplanted from warmer sites to cooler sites, this OTU was more 415 abundant that other transplanted communities. A similar pattern was observed for both 416 Anaerolinaceae and Desulfobacteraceae OTUs (Figure 4 A, C) with a negative correlation to 417 change in percent nitrogen. It was observed that in sample cores transplanted from sites high in 418 nitrogen to sites with lower concentrations, these two OTUs were more abundant than other 419 transplanted communities. Members of the sulfate-reducing Desulfobacteraceae are known to 420 degrade organic matter and release nutrients such as nitrogen and phosphorous (Pallud and Van 421 Cappellen, 2006). It is possible that the transplantation to a site with lower nitrogen may provide 422 additional metabolic niche space for this organism to increase in abundance or it may simply be a 423 significantly more hospitable environment than its origin. Relatively little is known about the metabolism of the Anaerolinaceae family (Yamada et al., 2006), but they may also play a role in the terminal mineralization of organic matter in low oxygen sites (Sinkko et al., 2013). The abundance of this OTU also correlated positively with increased temperature between origin and host sites (Figure 4B), which may suggest that warmer temperatures could facilitate taking advantage of new environmental niches. It is also important to note that the structure of the sediment cores varied between northern and southern sites, and that unknown factors relating to the sediment structure may limit mixing of transplanted and external microbial communities, thus potentially having an effect on the ability of external organisms to invade, colonize, or thrive in transplanted cores. While factors pertaining specifically to the structure of the cores were not measured in this study, we can infer from observed visual differences and from belowground biomass data collected in other studies (Angermeyer et al., 2015; Crosby et al., 2015) that northern sites have more un-degraded organic matter than in the south and are likely more porous and oxygen permeable. These differences may play a role in the abundance profiles observed for the Anaerolinaceae and Desulfobacteraceae OTUs by providing a more anoxic environment when transplanted to the southern sites.

The linear regression results raise the question of why organisms that are strongly correlated to an environmental variable maintain their original relative abundances after transplantation to a site with a large shift in that specific environmental variable. For example, if Vibrio does much better in warmer locations, why doesn't it flourish in transplants from the north moved to the south? Our observations highlight two important points. First, it is clear that the established microbial communities in our sediment transplants were resistant to significant invasion from the surrounding host marsh over the time scale of our experiment, especially among the more abundant taxa. However, an ordination analysis of the low abundance OTUs $(<5 \%$ across all samples) showed there is less definition between the northern and southern sites when these organisms are also considered (Supp. Figure 4). This result suggests that dispersal out of, or invasion into, the community is happening at a low rate, or possibly, that niche occupation is preventing large influxes of diverse colonizing microorganisms (Brockhurst et al., 2007). Second, our results suggest that salt marsh communities may be resistant to significant environmental shifts over the course of one growing season. We are beginning to learn more 454 about the temporal dynamics of salt march microbial communities (Bowen et al. 2009), but it is 
455 difficult to speculate over what time scales one would expect a transplanted community to 456 become indistinguishable from its host marsh. However, as mentioned above, several studies 457 from a variety of environments have shown that some transplanted communities may not 458 undergo substantial changes, even over relatively long periods of time. However, neither the

459

460

461

462

463

464

465

466

467

468

469

470

471

472

473

474

475

476

477

478

479

480

481

482

483

484

485

486

487

488

489

490

491

492

493

494

495

496

497

498

499

500

apparent resistance to invasion nor environmental change rules out the possibility that important, possibly large-scale, shifts are occurring in the active vs. dormant partitions of these microbial communities. It has been shown recently that the activity of salt marsh-associated microbial communities can respond drastically to environmental perturbations (Kearns et al. 2016), and this should be taken into account for future transplant studies if our findings of community compositional resilience are reflective of actual dispersal events.

Additional factors that we did not directly test are related to the impact of Spartina itself on the associated microbial community, and include the effects of the mortality of the northern transplants and the differences in plant genotypes between regions. The Spartina alterniflora contained in the transplant cores moved from the northern-most two sites to the southern-most two generally died or fared much more poorly than transplants from south to north (Crosby et al., 2017). Although we specifically avoided larger S. alterniflora roots, our sediment samples likely contained very fine roots that theoretically classify these communities as part of the rhizosphere, and therefore potentially subject to plant-related influences. It is likely that the death of the stems would have an effect on the root uptake of nutrients from the soil and/or the production of exudates, both of which might have an effect on root-associated microbes. We do not know how symbiotically-connected these organisms are in our system, but future transplant experimental designs may be better able to control for plant survival.

Secondly, a recent study by Bowen et al. (2017) found that natural microbial communities associated with the rhizosphere of another salt marsh plant, Phragmites australis, were strongly regulated by the specific lineage of $P$. australis from which they were sampled. Furthermore, the authors showed that when sterilized plants were grown in a common-garden experiment, they would, over time, accumulate distinct microbial communities that were again defined by the plant lineage. While this work is convincing, it is unclear how applicable the findings are to our $S$. alterniflora-associated microbial communities since $S$. alterniflora along the U.S. east coast is not divided into multiple obvious lineages. However, there is some evidence that genetic divergence exists in this species between northern and southern populations as demonstrated by haplotype variation (Blum et al., 2007), although the exact boundaries between haplotype populations are unclear as are the total extent of genetic differences. Regardless, future studies of microbial ecology in the $S$. alterniflora rhizosphere may greatly benefit from considering plant genotype among the potential environmental factors contributing to the determination of microbial communities.

\section{Conclusions}

While there is much work yet to be done in understanding the complex roles that dispersal and environmental selection play in driving the biogeography of microorganisms (Evans et al. 2017), this study adds new information from an estuarine system to the growing body of evidence that transplanted microbial communities can be resistant to large-scale compositional shifts over seasonal time scales. However, this study also demonstrates that despite the fact that the overall community composition was maintained, the abundances of some potential indicator organisms

PeerJ reviewing PDF | (2018:01:23423:1:1:NEW 14 Apr 2018) 
501 were strongly influenced by the environmental shifts experienced after transplantation. This 502 tension between general resistance to change (Bowen et al. 2009) and the specific adaption of 503 individual species should be a key area of future study in microbial biogeography. It underscores 504 not only the complexity of the big picture interactions between dispersal and environmental 505 selection, but also forces us to consider the cell-level mechanisms that act on dispersed 506 populations to control invasion, colonization and survival in new environments.

507

508 Acknowledgments

509 We thank Rika Anderson, Zoe Cardon, Caroline Fortunato, Heather Leslie, David Rand, Emily 510 Reddington, Sheri Simmons, Joe Vallino, Joe Vineis, and Daniel Weinreich for both laboratory 511 support and guidance during data analysis and interpretation. 
512 References

513 Almstrand R, Pinto AJ, Figueroa LA, Sharp JO. 2016. Draft Genome Sequence of a Novel

514

515

516

517

518

519

520

521

522

523

524

525

526

527

528

529

530

531

532

533

534

535

536

537

538

539

540

541

542

543

544

545

546

547

548

549

550

551

552

553

554

555

556 Desulfobacteraceae Member from a Sulfate-Reducing Bioreactor Metagenome. Genome Announcements 4:e01540-15.

Andam CP, Doroghazi JR, Campbell AN, Kelly PJ, Choudoir MJ, Buckley DH. 2016. A Latitudinal Diversity Gradient in Terrestrial Bacteria of the Genus Streptomyces. mBio 7:e02200-15.

Angermeyer A, Crosby SC, Huber JA. 2015. Decoupled distance-decay patterns between dsrA and 16S rRNA genes among salt marsh sulfate-reducing bacteria. Environmental Microbiology 18:75-86.

Balser T and Firestone M. 2005. Linking microbial community composition and soil processes in a California annual grassland and mixed-conifer forest. Biogeochemistry 73:395-415.

Bell T, Ager D, Song J, Newman J, Thompson I, Lilley A, Van der Gast C. 2005. Larger islands house more bacterial taxa. Science 308:1884.

Bell T. 2010. Experimental tests of the bacterial distance-decay relationship. ISME Journal 11:1357-1365.

Blum M, J, Bando K, J, Katz M, \& Strong D, R. 2007. Geographic structure, genetic diversity and source tracking of Spartina alterniflora. Journal of Biogeography 34:2055-2069.

Bond-Lamberty B, Bolton H, Fansler S, Heredia-Langner A, Liu C, McCue LA, Smith J, Bailey V. 2016. Soil Respiration and Bacterial Structure and Function after 17 Years of a Reciprocal Soil Transplant Experiment. PLoS ONE 11:e0150599.

Bowen J, L, Crump B, C, Deegan L, A. and Hobbie J, E. 2009. Salt marsh sediment bacteria: their distribution and response to external nutrient inputs. ISME Journal 3:924-934.

Bowen JL, Kearns PJ, Byrnes JEK, Wigginton S, Allen WJ, Greenwood M, Tran K, Yu J, Cronin JT, Meyerson LA. 2017. Lineage overwhelms environmental conditions in determining rhizosphere bacterial community structure in a cosmopolitan invasive plant. Nature Communications 8(1): 1-8.

Brockhurst MA, Colegrave N, Hodgson DJ, Buckling A. 2007. Niche occupation limits adaptive radiation in experimental microcosms. PLOS ONE 2:e193.

Caporaso JG, Bittinger K, Bushman FD, DeSantis TZ, Andersen GL, Knight R. 2010. PyNAST: a flexible tool for aligning sequences to a template alignment. Bioinformatics 26:266-267.

Caporaso JG, Kuczynski J, Stombaugh J, Bittinger K, Bushman FD, Costello EK, Fierer N, Peña AG, Goodrich JK, Gordon JI, Huttley GA, Kelley ST, Knights D, Koenig JE, Ley RE, Lozupone CA, McDonald D, Muegge BD, Pirrung M, Reeder J, Sevinsky JR, Turnbaugh PJ, Walters WA, Widmann J, Yatsunenko T, Zaneveld J, Knight R. 2010. QIIME allows analysis of high-throughput community sequencing data. Nature Methods 7:335-336.

Case DH, Pasulka AL, Marlow JJ, Grupe BM, Levin LA, Orphan VJ. 2015. Methane Seep Carbonates Host Distinct, Diverse, Dynamic Microbial Assemblages. mBio 6:e01348-15.

Comte J, Fauteux L, del Giorgio PA. 2013. Links between metabolic plasticity and functional redundancy in freshwater bacterioplankton communities. Frontiers in Microbiology 4:112.

Crosby SC, Angermeyer A, Adler JM, Bertness MD. 2017. Spartina alterniflora biomass allocation and temperature: implications for salt marsh persistence with sea-level rise. Estuaries and Coasts 40:213-223 DOI:10.1007/s12237-016-0142-9.

Crosby SC, Ivens-Duran M, Bertness MD, Davey E, Deegan LA, Leslie HM. 2015. Flowering and biomass allocation in U.S. Atlantic coast Spartina alterniflora. American Journal of

557 Botany 102:669-676 DOI:10.3732/ajb.1400534. 
558

559

560

561

562

563

564

565

566

567

568

569

570

571

572

573

574

575

576

577

578

579

580

581

582

583

584

585

586

587

588

589

590

591

592

593

594

595

596

597

598

599

600

601

602

603

Eren AM, Maignien L, Sul WJ, Murphy LG, Grim SL, Morrison HG, Sogin ML. 2013. Oligotyping: Differentiating between closely related microbial taxa using 16S rRNA gene data. Methods in Ecology and Evolution 4:1111-1119.

Eren AM, Vineis JH, Morrison HG, Sogin ML. 2013. A filtering method to generate high quality short reads using illumina paired-end technology. PLoS ONE 8:e66643.

Evans S, Martiny JBH., Allison SD. 2017. Effects of dispersal and selection on stochastic assembly in microbial communities. ISME Journal 11:176-185.

Fortunato CS, Eiler A, Herfort L, Needoba JA, Peterson TD, Crump BC. 2013. Determining indicator taxa across spatial and seasonal gradients in the Columbia River coastal margin. ISME Journal 7:1899-1911.

Gasol J, Comerma M, Garcia J, Armengol J, Casamayor E, Kojecka P, Simek K. 2002. A transplant experiment to identify the factors controlling bacterial abundance, activity, production, and community composition in a eutrophic canyon-shaped reservoir. Limnology and Oceanography 47:62-77.

Hanson CA, Fuhrman JA, Horner-Devine MC, Martiny JBH. 2012. Beyond biogeographic patterns: processes shaping the microbial landscape. Nature Reviews Microbiology 10:497506.

Horner-Devine MC., Lage M, Hughes JB., Bohannan BJM. 2004. A taxa-area relationship for bacteria. Nature 432:750-753 DOI:10.1038/nature03073.

Huse SM, Dethlefsen L, Huber JA, Welch DM, Relman DA, Sogin ML. 2008. Exploring microbial diversity and taxonomy using SSU rRNA hypervariable tag sequencing. PLoS Genetics 4:e1000255.

Huse SM, Huber JA, Morrison HG, Sogin ML, Welch DM. 2007. Accuracy and quality of massively parallel DNA pyrosequencing. Genome Biology 8:R143.

Huse SM, Mark Welch DB, Voorhis A, Shipunova A, Morrison HG, Eren AM, Sogin ML. 2014. VAMPS: a website for visualization and analysis of microbial population structures. $B M C$ Bioinformatics 15:41.

Jones E, Oliphant E, Peterson P. 2001. SciPy: Open Source Scientific Tools for Python. www.scipy.org

Kearns PJ, Angell JH, Howard EM, Deegan LA, Stanley RHR, Bowen JL. 2016. Nutrient enrichment induces dormancy and decreases diversity of active bacteria in salt marsh sediments. Nature Communications 7:12881 DOI:10.1038/ncomms12881.

Lazzaro A, Gauer A, Zeyer J. 2011. A field-scale transplantation experiment to investigate structures of soil bacterial communities at pioneering sites. Applied and Environmental Microbiology 77:8241-8248.

Livermore JA and Jones SE. 2015. Local-global overlap in diversity informs mechanisms of bacterial biogeography. ISME Journal 9:2413-2422.

Mantel N. 1967. The detection of disease clustering and a generalized regression approach. Cancer Research 27:209-220.

Martin A, Anderson MJ, Thorn C, Davy SK. 2011. Response of sea-ice microbial communities to environmental disturbance: an in situ transplant experiment in the Antarctic. Marine Ecology Progress Series 424:25-37.

Martiny JBH, Bohannan BJM, Brown JH, Colwell RK, Fuhrman JA, Green JL, Horner-Devine MC, Kane M, Krumins JA, Kuske CR, Morin PJ, Naeem S, Ovreås L, Reysenbach A-L, Smith VH, Staley JT. 2006. Microbial biogeography: putting microorganisms on the map. Nature Reviews Microbiology 4:102-112. 
604

605

606

607

608

609

610

611

612

613

614

615

616

617

618

619

620

621

622

623

624

625

626

627

628

629

630

631

632

633

634

635

636

637

638

639

640

641

642

643

644

645

646

647

648

649

Martiny JBH., Eisen JA, Penn K, Allison SD, Horner-Devine MC. 2011. Drivers of bacterial beta-diversity depend on spatial scale. PNAS 108:7850-7854.

McDonald D, Price MN, Goodrich J, Nawrocki EP, DeSantis TZ, Probst A, Andersen GL, Knight R, Hugenholtz P. 2012. An improved Greengenes taxonomy with explicit ranks for ecological and evolutionary analyses of bacteria and archaea. ISME Journal 6:610-618.

McDougald D, Rice SA, Barraud N, Steinberg PD, Kjelleberg S. 2011. Should we stay or should we go: mechanisms and ecological consequences for biofilm dispersal. Nature Reviews Microbiology 10:39-50.

Morrissey EM and Franklin RB. 2015. Evolutionary history influences the salinity preference of bacterial taxa in wetland soils. Frontiers in Microbiology 6:1013.

Nemergut DR, Schmidt SK, Fukami T, O'Neill SP, Bilinski TM, Stanish LF, Knelman JE, Darcy JL, Lynch RC, Wickey P, Ferrenberg S. 2013. Patterns and processes of microbial community assembly. Microbiology and Molecular Biology Reviews 77:342-356.

Oakley BB, Carbonero F, van der Gast CJ, Hawkins RJ, Purdy KJ. 2010. Evolutionary divergence and biogeography of sympatric niche-differentiated bacterial populations. ISME Journal 4:488-497.

Pallud C, Van Cappellen P. 2006. Kinetics of microbial sulfate reduction in estuarine sediments. Geochimica et Cosmochimica Acta 70:1148-1162.

Pfeffer CS, Hite MF, Oliver JD. 2003. Ecology of Vibrio vulnificus in Estuarine Waters of Eastern North Carolina. Applied and Environmental Microbiology 69:3526-3531.

Rawls JF, Mahowald MA, Ley RE, Gordon JI. 2006. Reciprocal gut microbiota transplants from zebrafish and mice to germ-free recipients reveal host habitat selection. Cell 127:423-433.

Reed HE and Martiny JBH. 2013. Microbial composition affects the functioning of estuarine sediments. ISME Journal 7:868-879.

Reed HE and Martiny JBH. 2007. Testing the functional significance of microbial composition in natural communities. FEMS Microbiology Ecology 62:161-170.

Rui J, Li J, Wang S, An J, Liu W-T, Lin Q, Yang Y, He Z, Li X. 2015. Responses of Bacterial Communities to Simulated Climate Changes in Alpine Meadow Soil of the Qinghai-Tibet Plateau. Applied and Environmental Microbiology 81:6070-6077.

Schloss PD, Westcott SL, Ryabin T, Hall JR, Hartmann M, Hollister EB, Lesniewski RA, Oakley BB, Parks DH, Robinson CJ, Sahl JW, Stres B, Thallinger GG, Van Horn DJ, Weber CF. 2009. Introducing mothur: open-source, platform-independent, community-supported software for describing and comparing microbial communities. Applied and Environmental Microbiology 75:7537-7541.

Schmidt VT, Reveillaud J, Zettler E, Mincer TJ, Murphy L, Amaral-Zettler LA. 2014. Oligotyping reveals community level habitat selection within the genus Vibrio. Frontiers in Microbiology 5:563.

Sinkko H, Lukkari K, Sihvonen LM, Sivonen K. 2013. Bacteria contribute to sediment nutrient release and reflect progressed eutrophication-driven hypoxia in an organic-rich continental sea. PLoS ONE 8:e67061.

St John MG, Orwin KH, Dickie IA. 2011. No 'home' versus “away” effects of decomposition found in a grassland-forest reciprocal litter transplant study. Soil Biology and Biochemistry 43:1482-1489.

R Core Team. 2014. R: A language and environment for statistical computing. http://www.Rproject.org/

Thompson JR, Randa MA, Marcelino LA, Tomita-Mitchell A, Lim E, Polz MF. 2004. Diversity 
650 and Dynamics of a North Atlantic Coastal Vibrio Community. Applied and Environmental 651 Microbiology 70:4103-4110.

652 van der Gast CJ. 2014. Microbial biogeography: the end of the ubiquitous dispersal hypothesis? 653 Environmental Microbiology 17:544-546.

654 Waldrop MP and Firestone MK. 2006. Response of Microbial Community Composition and 655 Function to Soil Climate Change. Microbial Ecology 52:716-724.

656 Yamada T, Sekiguchi Y, Hanada S, Imachi H, Ohashi A, Harada H, Kamagata Y. 2006.

657

658

659

660

661

662

663 Anaerolinea thermolimosa sp. nov., Levilinea saccharolytica gen. nov., sp. nov. and Leptolinea tardivitalis gen. nov., sp. nov., novel filamentous anaerobes, and description of the new classes Anaerolineae classis nov. and Caldilineae classis nov. in the bacterial phylum Chloroflexi. International Journal of Systematic and Evolutionary Microbiology 56:1331-1340.

Zinger L, Boetius A, Ramette A. 2014. Bacterial taxa-area and distance-decay relationships in marine environments. Molecular Ecology 23:954-964 DOI:10.1111/mec.12640. 


\section{Figure 1}

Geographic locations of U.S. easy coast study sites.

Locations of salt marsh sediment sampling sites. WB-Waquoit Bay, PI-Prudence Island, JRJones River, RC-Rachael Carson, AB-ACE Basin. Symbols are used to refer to each site in following figures. Base map provided by freevectormaps.com. 


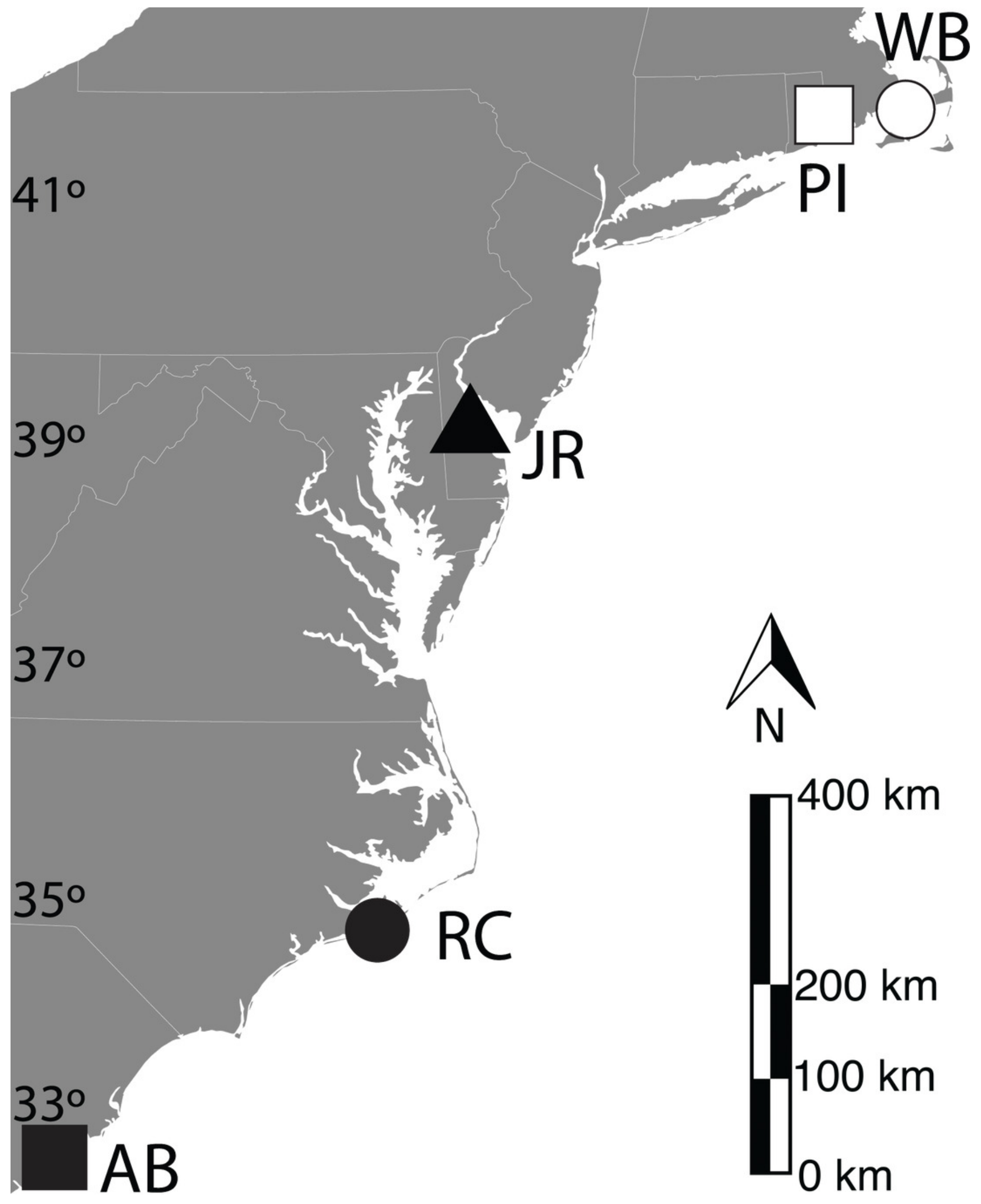




\section{Figure 2}

Relative abundance of bacterial 16S rRNA genes among transplant samples and controls.

Taxonomic assignments for bacterial 16S rRNA genes were based on 97\% sequence similarity. Only taxa that occur in $\geq 5 \%$ abundance in any individual sample are colored. Blocks of samples are arranged by origin site (north to south), and by destination site within each block. The last three columns in each block are the pristine controls. The hatched columns are the Vibro sp. subset of Gammaproteobacteria. Grey columns represent all taxa $<5 \%$ abundance and two samples that did not amplify.

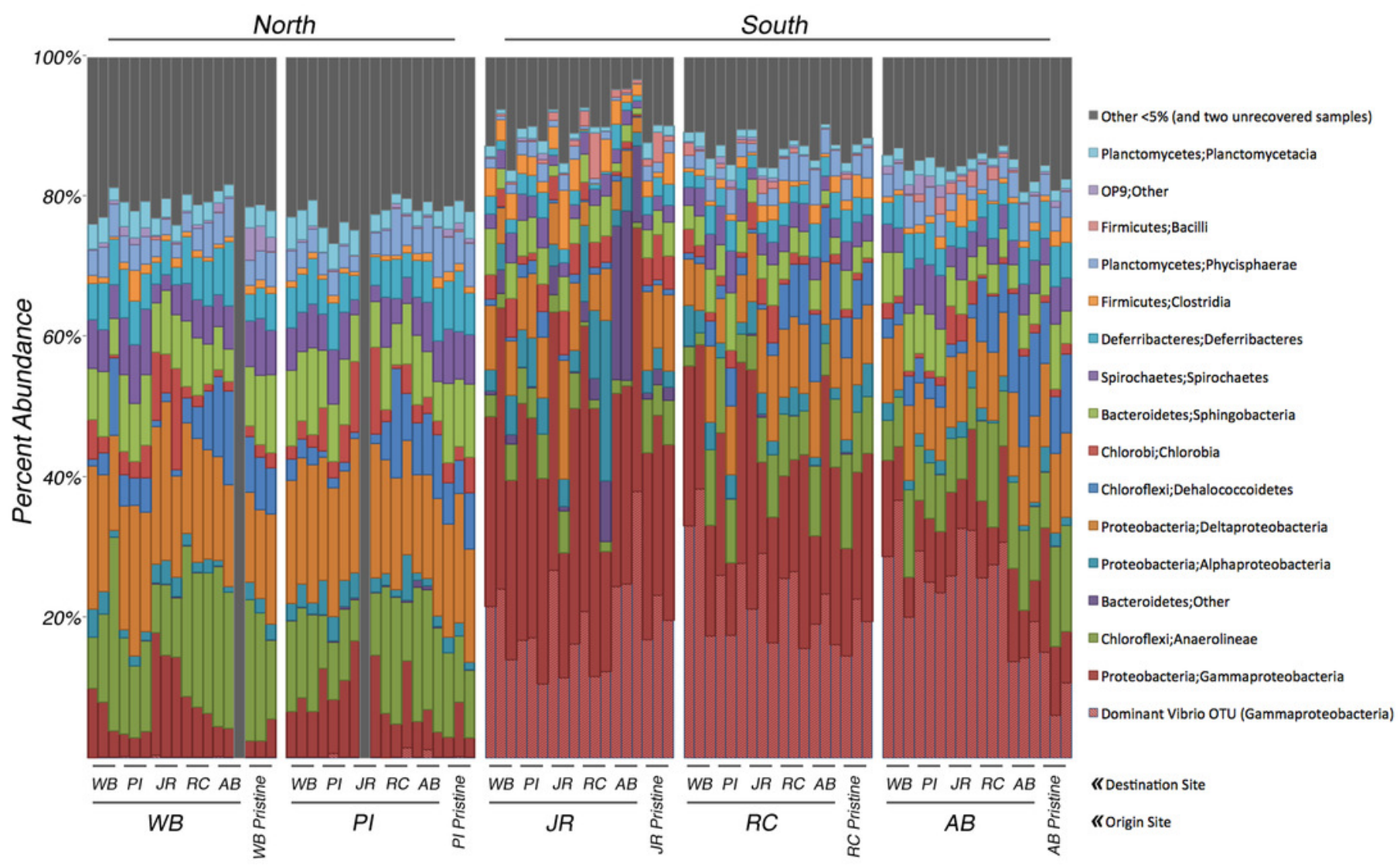


Figure 3

nMDS ordination plots of transplant samples and controls.

(A) All 16S rRNA gene OTUs for control samples; (B) Top ten most abundant 16S rRNA gene OTUs for control samples; (C) All 16S rRNA gene OTUs for all samples; and (D) Top ten most abundant 16S rRNA gene OTUs for all samples. 'Red' symbols are pristine control samples, 'black' are transplant samples. Transplant samples are labeled by origin site.

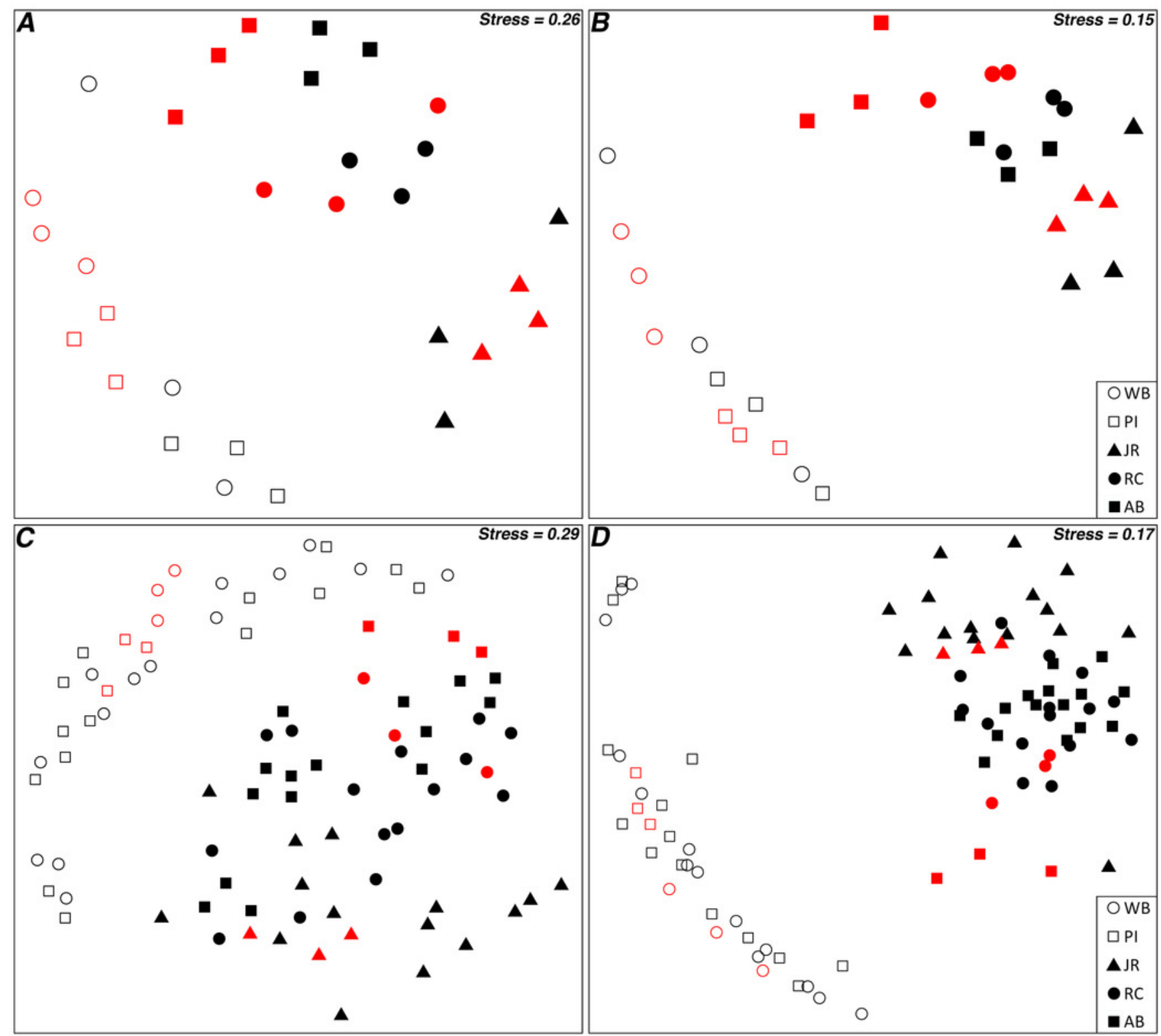


Figure 4

Linear regression plots of indicator OTUs.

16S rRNA gene OTUs percent abundance (by sample) as a function of change in a specific environmental variable for (A) Anaerolinaceae and nitrogen; (B) Anaerolinaceaea and temperature; (C) Desulfurobacteraceae and nitrogen; and (D) Vibrio and temperature. Equations, R-squared values and p-values of each linear regression are provided.
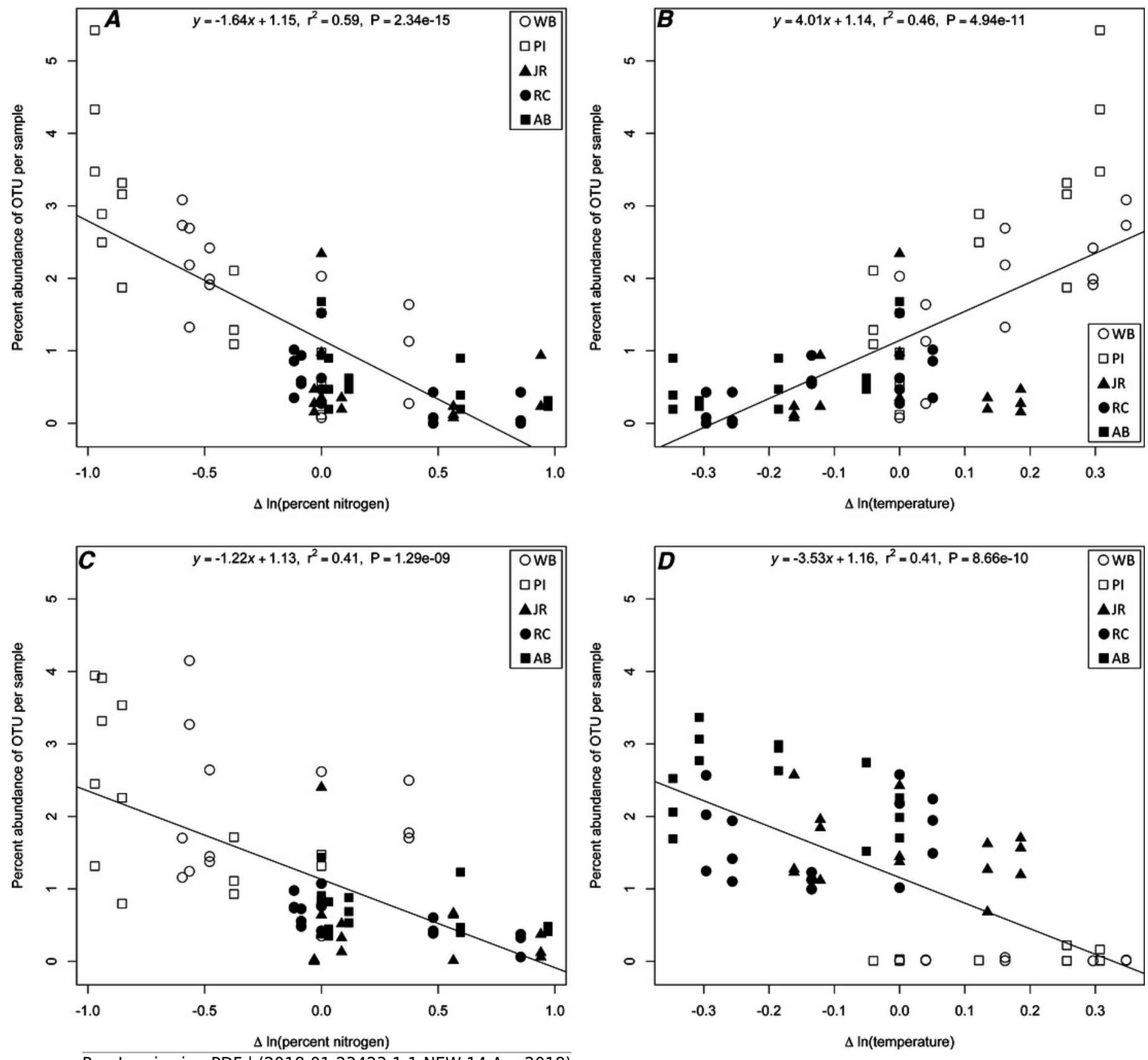


\section{Table $\mathbf{1}$ (on next page)}

Site locations and environmental variables.

Sites are listed north to south. Nitrogen and carbon values are percent by weight. 
Site Lat. $\left({ }^{\circ} \mathrm{N}\right) \quad$ Lon. $\left({ }^{\circ} \mathrm{W}\right) \quad \% \mathrm{~N}(\mathrm{Wt}) \quad \% \mathrm{C}(\mathrm{Wt}) \quad$ Salinity (ppt) Air temp $\left({ }^{\circ} \mathrm{C}\right)$

$\begin{array}{lllllll}\text { WB } & 41.580 & 70.521 & 0.92 & 13.85 & 25.1 & 17.1 \pm 6.3\end{array}$

$\begin{array}{lllllll}\mathrm{PI} & 41.625 & 71.324 & 1.34 & 23.58 & 26.6 & 17.8 \pm 6.5\end{array}$

$\begin{array}{lllllll}\text { JR } & 39.089 & 75.437 & 0.52 & 5.99 & 10.7 & 20.1 \pm 7\end{array}$

$\begin{array}{lllllll}\text { RC } & 34.723 & 76.675 & 0.57 & 8.78 & 32.3 & 23 \pm 5.6\end{array}$

1

$\begin{array}{lllllll}A B & 32.558 & 80.439 & 0.51 & 8.59 & 26.4 & 24.2 \pm 5.7\end{array}$

